\title{
A construção social dos corpos periféricos
}

\section{The social construction of peripheral bodies}

\section{Luís Fernandes}

Universidade do Porto. Faculdade de Psicologia e de Ciências da Educação. Porto, Portugal.

E-mail: jllfœfpce.up.pt

\section{Raquel Barbosa}

Universidade do Porto. Faculdade de Psicologia e de Ciências da Educação. Centro de Psicologia da Universidade do Porto. Porto, Portugal.

E-mail: raquelळfpce.up.pt

\section{Correspondência}

Rua Alfredo Allen. Porto, Portugal. CEP 4200-135.

\section{Resumo}

Este artigo desenvolve o seu argumento em torno da forma como lidamos socialmente com corporalidades que se afastam da centralidade corpórea, entendida aqui como o resultado da valorização de determinados aspetos do corpo, que passam a ser tomados como modelo do que este deve ser. Começando por situar o corpo como objeto privilegiado para a comunicação entre o biológico, o individual e o sociocultural, esclarece os conceitos que servirão à nossa análise: corporalidade, centralidade corpórea, símbolo natural e incorporação. Interroga o porquê da ascensão do corpo nas sociedades do hiperindividualismo contemporâneo e procura evidenciar processos sociais em curso que produzem normas sobre o que o corpo deve ser, e que metaforizamos com as imagens dos corpos na marquesa, na passerelle e no podium. Propõe-se em seguida a noção de corpo periférico como aquele do qual emanam signos desvalorizados pelos padrões constituintes da centralidade corpórea. Exemplificamos com as deformidades físicas e com a obesidade, analisando a partir delas como pode o corpo constituir-se como fonte de estigma e locus de sofrimento psicológico nos processos interativos correntes. 0 percurso que aqui empreendemos é suscetível de fornecer elementos para as seguintes questões analíticas que atravessam todo o texto: que processos conduzem um determinado objeto social a tornar-se central ou, pelo contrário, a ser deslocado para a periferia? Como construímos socialmente o periférico? Que consequências pode ter nas vivências psicológicas e na vida social daqueles que são olhados como corpos periféricos?

Palavras-chave: Corpo; Corporalidade; Estigma; Construção Social; Obesidade; Deformidade Física. 


\section{Abstract}

This paper focuses on the ways our societies deal with non-central corporalities, that is, those corporalities that depart from the socially constructed standard model of what the body should be.

It begins by taking the body as a privileged locus for the communication between the biological, the individual and the sociocultural, and defining the core concepts of the ensuing analysis: corporality, bodily centrality, natural symbol, and incorporation. It then moves on to question the rise of the body in the contemporary, hiperindividualistic societies, and highlights social processes that produce the norms about what the body should be. Such norms turn into metaphors the images of bodies on the examination table, the passerelle and the podium. We then present the notion of the peripheral body as that from which emanates signs that are devalued by the standards of body centrality. Physical deformities and obesity are shown as examples of how the body can be a source of stigma and the locus of psychological suffering in common interaction processes. We attempt to provide elements for the analytical questions that run through the paper: what processes lead a given social object to become a part of the center or, on the contrary, be relegated to the periphery? How the peripheral is socially constructed? What are the social and psychological consequences of being seen as a peripheral body? Keywords: Body; Corporality; Stigma; Social Construction; Obesity; Physical Deformities.

\section{Corpo, indivíduo e corpo social: interdeterminações}

A vida humana é revestida pelos poderes e saberes que caracterizam uma determinada época, acompanhando o desenvolvimento das diversas transformações ocorridas nas sociedades. Tendo como referência o corpo, a vida apresenta-se como um facto intra e intersubjetivo, no qual o consciente e o inconsciente, o biológico e o psíquico, o individual e o social, a natureza e a cultura interagem, visando-se o sentido mais pleno da existência. Partilhamos inteiramente a advertência de Pereira quando escreve que "talvez ciências sociais e biomedicina tenham mais em comum do que estamos (os cientistas sociais) dispostos a admitir. Não obstante as diferenças enunciadas de parte a parte, os dilemas da tradução e os sérios problemas daí advindos, muitas vezes cientistas sociais e biomédicos acabam por compactuar uma grande divisão como regra básica do jogo: a divisão entre natureza e cultura" (Pereira, 2011, p. 66).

\section{A proposta a desenvolver: a produção dos corpos periféricos}

O corpo é, pois, um objeto privilegiado para a análise das interdeterminações entre o indivíduo e o social. A posição analítica em que queremos colocar o corpo ao longo deste texto está claramente expressa numa afirmação que encontrámos em Jung (1996, p. 5): "Pertencente ao mundo do visível e sensível, o corpo é o cordão umbilical com o social. Ser social é em primeiro lugar ser intercorporal".

O corpo, entendido nesta interface entre o indivíduo e o social, está sujeito a regimes de normatividade. Dito doutro modo, está constrangido pelas regras que asseguram certa normalidade na vida social corrente. Assim como há uma ordem do discurso inspiramo-nos em Foucault (1971) -, assim como há uma ordem na interação quotidiana - inspiramo-nos agora em Goffman (1963a) -, há uma ordem corporal ${ }^{1}$.

1 As investigações que se debruçaram sobre as subculturas juvenis dos anos 1960 e 1970 do século XX, levadas a cabo pelo Center for Contemporary Cultural Studies - conhecido hoje como Escola de Birmingham - mostrou como os jovens dessa época construíam todo um visual como forma de resistência às formas adultas do estar em sociedade. Criar uma cultura alternativa passava por exibir o corpo como lugar de expressão do desvio ao conformismo straight do mundo dos adultos. Nos anos 1970, a subcultura punk levaria este recurso ao exagero, utilizando a corporalidade como instrumento explícito de choque, de revolta e de transgressão. Ver, respectivamente, o clássico da Escola de Birmingham coordenado por Hall e Jefferson (1975) e Langman (2008). 
A ordem pressupõe um centro e sucessivos afastamentos por referência a este. "A ideia de centralidade, por sua vez, tem a universalidade como pressuposto. Quando se fala no 'centro' de uma cidade, por exemplo, parte-se da premissa de que existe uma parcela específica de seu território passível de ser reconhecida por todos como tal, independentemente de qual seja o local de moradia, a condição econômica, a etnia, a crença religiosa ou a preferência artística da pessoa ou do grupo social considerado" (Pereira, 2012).

O espaço urbano, com as suas centralidades e periferias, serve-nos aqui de metáfora para o exercício que queremos levar a cabo: o de considerar o corpo no jogo entre a centralidade e a construção social de periferias em relação a esta. Chamaremos "corpos periféricos" os que se situam nesta periferia. Para tal, necessitamos em primeiro lugar de esclarecer como se constitui uma "centralidade corpórea" em relação à qual podem produzir-se posições periféricas.

Não é este exercício um mero jogo conceptual - o que já seria legítimo por si mesmo, dado que a teoria não precisa de razões práticas para existir no espaço das ideias - mas um esforço para compreender processos sociais que resultam em fenómenos de estigma e de rejeição na esfera individual. É justamente porque a relação social é intercorporal que uma dada corporalidade se presta a ser fonte de sociabilidades ou de rejeições, se presta a ser fonte de autoconfiança e de prazer ou, pelo contrário, de baixa autoestima e de sofrimento. Agostinho Ribeiro sintetiza-o bem quando escreve:

Mas dificilmente este olhar exterior sobre o nosso corpo-objecto deixará de evocar gratificações e frustrações, sensuais e sociais, que ele nos proporcionou ou promete: corpo gozado ou corpo sofrido, corpo apreciado ou menosprezado, desejado ou rejeitado (Ribeiro, 1996, p. 39).

\section{Alguns conceitos necessários}

Ao propormo-nos a este exercício precisamos de lançar mão de alguns conceitos que têm sido desenvolvidos por várias disciplinas - essencialmente a psicologia, a sociologia e a antropologia - de modo a darmos rigor analítico à nossa proposta em torno dos corpos periféricos.

Estaremos em primeiro lugar a considerar, mais do que o corpo na sua realidade física, a corporalidade. Situemos aquilo a que nos referimos com o termo corporalidade ou, utilizando um sinónimo, corporeidade. A sociologia do corpo nomeou como seu objeto de estudo não o organismo humano mas a corporeidade, enquanto conjunto de manifestações simbólicas da existência corporal, devidamente contextualizado no tempo histórico e no espaço social (Ferreira, 2013).

Berthelot (1983 apud Ferreira, 2013) diz-nos que:

Se entendermos por corporeidade o conjunto de traços concretos do corpo como ser social, diremos que uma dada sociedade define simultaneamente um certo espaço de corporeidade (ou seja, um número de possíveis corporais, formado por regras de conveniência na apresentação e na gestão do corpo) e uma certa corporeidade modal (ou seja, um conjunto determinado de traços valorizados) (p. 499).

Sem perder de vista a distinção que acabámos de fazer, ao longo deste texto utilizaremos como sinónimos "corpo" e "corporalidade", alinhando-nos assim com a literatura nesse domínio, que fala muitas vezes de "corpo" para dizer "corporalidade"/"corporeidade".

Continuando a clarificar conceptualmente o exercício que aqui levamos a cabo, diremos que estamos próximos do conceito de símbolo natural, de Douglas (1970), antropóloga que concebeu o corpo como "símbolo natural", chamando a atenção para o complexo relacionamento entre os aspectos físicos e sociais que comporta. O vocábulo "natural" diz respeito ao modo como naturalizamos aspectos do funcionamento corporal, perdendo de vista a matriz social que os estruturou. Explora as propriedades simbólicas do corpo, incluindo os seus orifícios, secreções e dejetos ("poluição"), considerando o corpo físico como modelo social: a experiência física é sempre mediada e modificada através de categorias sociais.

Ainda de acordo com a autora, os orifícios corporais, tais como a matéria que deles é expelida, 
são símbolos potentes de poder e perigo, poluição e tabu. Os rituais de demarcar, separar e castigar a transgressão têm, assim, como principal função a imposição de um sistema de ordem simbólica naquilo que é considerado uma experiência “suja”.

Uma recente e interessante aplicação dessa perspetiva encontra-se no trabalho etnográfico levado a cabo por Taniele Rui na Cracolândia de São Paulo com os usuários de crack. Propõe a noção de "corpos abjetos" para descrever a experiência de extrema dependência dos "noias", os mais atingidos pelas consequências drásticas da dependência química e da vida na rua. E diz-nos (Rui, 2012):

Os seus corpos causam abjeção menos pela falta de limpeza ou pela possibilidade de transmissão de fluidos/doenças e mais porque perturbam ficções de identidade, sistema e ordem; porque não respeitam fronteiras, posições e regras; em suma, porque são ambíguos. Tais corpos estão às margens, no sentido proposto por Veena Das e Deborah Poole (2008), ocupando brechas nos espaços entre a lei e a disciplina e, nesse sentido, expressando tanto perigo quanto poder (Douglas, 1966). (p. 26).

Veremos adiante como esta problematização nos será útil para situarmos o que entendemos por “corpos periféricos". Mas atentemos ainda no que nos diz Douglas (1970):

O corpo social condiciona o modo como percebemos o corpo físico. A experiência física do corpo, modificada sempre pelas categorias sociais através das quais conhecemos, mantém uma visão particular da sociedade. Existe uma contínua troca de significados entre os dois tipos de experiência, de forma que cada uma reforça as categorias da outra. Como resultado desta interação, o corpo em si mesmo é um meio altamente restrito de expressão (p. 73) ${ }^{2}$.

A palavra corpo está carregada culturalmente não dizemos sempre a mesma coisa ao dizer corpo, falamos dele conferindo-lhe vários sentidos. O'Neill (1985) identificou pelo menos cinco: o "corpo do mundo" diz respeito à tendência humana a antropomorfizar o cosmos; o "corpo social" refere-se à analogia das instituições sociais com o nosso corpo e ao uso dos processos corporais, como a ingestão de comida, para definir categorias sociais; o "corpo político" diz respeito a modelos de cidade ou campo, formando a base de palavras como cabeça de Estado ou membros do corpo político; o "corpo consumista" refere-se à criação e comercialização das necessidades corporais, de que o exemplo mais evidente é o sexo; o "corpo médico", que se refere ao processo de medicalização, ao controle médico e à tecnologia a qual um crescente número de processos corporais está sujeito. Na secção seguinte utilizaremos a expressão "corpo na marquesa” num sentido próximo do "corpo médico" de O’Neill.

O corpo é, como temos constatado pelo exposto, ponte de ligação do indivíduo com o mundo, e a corporalidade é central na construção da sua identidade e autoestima ${ }^{3}$. Mas, se psiquismo e corpo estão ligados no todo que é o indivíduo, corpo e corpo social têm também ligações estreitas. Assim como há uma ordem social, há uma ordem corporal - e desvios a essa ordem. A ordem corporal inicia e revela a ordem social. A escola primária é o lugar inicial da imposição da ordem corporal: o estar sentado, o olhar o professor, o não falar, o aguardar a vez, o conter os gestos, o controle das necessidades fisiológicas. Esta ordem corporal é, por sua vez, a base da ordem que a sala de aula

\footnotetext{
2 Mary Douglas, tal como fizera já Marcel Mauss, traz o tema do corpo para as preocupações centrais da antropologia. Para uma revisão do tema do corpo na tradição antropológica ver Almeida (2004), e para a modelagem cultural do corpo e dos seus usos ver Separavich e Canesqui (2010).

${ }^{3}$ Apesar de ser esta uma afirmação suscetível de recolher largo consenso, as escolas dominantes da psicologia seguiriam uma linha mentalista - como que se a vida psíquica fosse uma realidade desligada do corpo. Outra trajetória teria, com certeza, acontecido se a fenomenologia de Merleau Ponty tivesse tido a mesma influência daquelas. Na sua conceção, o corpo apresenta-se como uma estrutura única, é a base sobre a qual se sustenta a existência e onde se revelam diversas manifestações como as afetivas, intelectuais, eróticas, cognitivas e sensitivas, responsáveis pela relação do sujeito com o mundo, de modo que a consciência e o pensamento não possam atuar de maneira absoluta, mas sim em interdependência com estas outras potências.
} 
exige - e a ordem na sala de aula é a base da ordem que a sociedade exige ${ }^{4}$.

O modelo escolar da sala de aula foi já descrito por Foucault (1975) como o paradigma moderno da disciplinarização dos corpos, como locus privilegiado da realização exaustiva dos exercícios, dos exames, das punições e recompensas. Lugar de adestramento e de docilização dos corpos em ordem à sua utilidade revela bem as estratégias de controle soft que caracterizariam a sociedade disciplinar, difundidas e multiplicadas em todas as repartições do social, do quartel à fábrica, do hospital à prisão (Foucault, 1975).

Do corpo ao corpo social, do corpo social ao corpo: estamos perante uma circularidade que exemplifica os processos de incorporação. "A incorporação surge como conceito chave nesta tradição analítica (da sociologia do corpo) dando conta do processo corporal de "interiorização não-verbal, inconsciente, mimética, automática, de certas disposições de desigualdade e de poder" (Almeida, 1996 apud Ferreira, 2013).

Corpo como símbolo natural da sociedade em Mary Douglas, corpos dóceis e úteis em Michel Foucault, incorporação na tradição da sociologia do corpo: linguagens distintas para caracterizar o mesmo processo instituinte, em que o social molda e constrange a expressão natural do corpo e este, simultaneamente, faz falar o social no modo como se move e projeta aparências.

É pelo seu valor sensual, e sobretudo pelas suas funções identitária e social, que em todas as civilizações humanas existem normas de governo do corpo e cuidados com a aparência corporal. A convergência de motivações individuais, pressupostos ideológicos e pressões sociais, determina, em cada caso concreto, se tais preocupações irão no sentido de libertar e exaltar o corpo, de o sentir e gozar ou, ao contrário, de o amordaçar, de o oprimir, de o esquecer, de o sofrer (Ribeiro, 1996, p. 39).

\section{Centralidade corpórea}

Depois do percurso feito na secção anterior, estamos em condições de dizer que, se quisermos perceber o modo como construímos a periferia, podemos começar pela corporalidade. As primeiras distâncias e discriminações começam a propósito dela, como saberá por experiência própria quem foi obeso na infância... Mas pouco nos detemos para pensar nisso, pois o projeto da modernidade, que andámos a concretizar durante os últimos séculos, foi o da afirmação da razão: o século das luzes, depois o século das ciências positivas, depois o século da racionalidade instrumental, são tempos de afirmação das conquistas espirituais, que nos desabituaram de nos relacionarmos com a parte mais física da nossa presença no mundo.

A psicanálise, que emerge no final do século XIX, é um bom exemplo do que fizemos com o corpo: ela nasceu em grande medida para descobrir o que se tornava a energia institual que o modelo cultural vigente obrigava a conter, a reprimir, a negar, a recalcar. Uma parte dessa energia retornava sob a forma de sintoma, processo particularmente visível na neurose histérica, pois o retorno tinha como lugar de fixação o próprio corpo, fazendo falar a neurose a partir dele, como se esta retornasse precisamente ao ponto onde começou a se formar, desenvolvendo-se a interpretação psicanalítica como técnica de descodificação da linguagem corporal. Mas até ela caiu na contradição de, reconhecendo a ligação do sintoma psicológico à sexualidade, ao corpo e à sua energia libidinal, ter inventado um método interventivo que utiliza apenas o intelecto e a linguagem verbal 5 .

$\mathrm{O}$ advento da máquina e, já bem entrados no século XX, da automação, ao mesmo tempo que dispensou o corpo de uma grande parte do esforço que o trabalho lhe exigia, convocam-no a um novo papel não menos exigente. As novas tecnologias de produção em massa desencadearam um processo de homogeneização de gestos e hábitos que se estendeu a outras esferas sociais, entre elas a educação do corpo, que passou a se

\footnotetext{
4 É a este respeito muito revelador o modo como a disciplina escolar é utilizada já desde o século XVIII como instrumento de normalização do desvio infanto-juvenil. No caso português remonta a 1780, com a fundação da Casa Pia de Lisboa, que tinha como mandato social retirar os rapazes à vagabundagem de rua para, através da escolarização, os encaminhar para os ofícios tornando-os súbditos ordeiros e úteis (ver Martins, 2010).
} 
identificar não só com as técnicas, mas também com os interesses da produção (Hobsbawm, 1996 apud Pelegrini, 2006). Assim, o ser humano é colocado a serviço da economia e da produção, gerando um corpo produtor que, portanto, precisa de ter saúde para melhor produzir e precisa de adaptar-se aos padrões de beleza para melhor consumir. Encaminhamo-nos para duas forças produtoras de corporalidade modal, que mais à frente desenvolveremos ao falar dos corpos na marquesa e na passerelle.

Nas últimas décadas, o corpo tem conquistado novo protagonismo, em um contexto marcado pelo favorecimento da atomização social e do consequente ganho de espaço da esfera individual - algo que alguns analistas chamam de hiperindividualismo contemporâneo. Le Breton (1999) considera que a paixão individualista pelo corpo é consequência da estruturação individualista das nossas sociedades, sobretudo nesta fase narcisista - o que reforça a tese enunciada uma década antes por Lipovetsky (1989). Os atuais regimes que instauraram a vontade da sua modificação (Le Breton dá o exemplo extremo das cirurgias plásticas) têm de afetar profundamente a experiência do indivíduo - desde logo na sua identidade, no modo como olha para os outros e como acha que os outros olham para ele.

Na sociedade dos indivíduos - seja-nos permitido tomar de empréstimo a expressão a um título de Norbert Elias -, o corpo assume um novo papel enquanto instrumento de relação com o mundo. Segundo Turner (1996), enquanto no início do capitalismo havia uma relação entre a disciplina, o ascetismo, o corpo e a produção, no capitalismo tardio existe uma ênfase no hedonismo, no desejo e no divertimento. 0 corpo é construído, decorado e expressa-se individualmente; é um projeto pessoal, flexível e adaptável aos desejos do indivíduo (Turner, 1996). Essa análise é convergente em vários autores que têm analisado os múltiplos sinais de uma transição em curso - dos quais poderíamos destacar Maffesoli, Giddens ou Lipovetsky - e está bem sintetizada no seguinte excerto:
Só na segunda metade deste século [XX] pudemos assistir a uma clara recuperação dos valores corporais, aliás uma das mudanças de maior impacto associadas à passagem para a pós-modernidade [...] Três escassas décadas passadas, os corpos da actual geração, "radical" e "sem limites", imersa já numa cultura do prazer e do espectáculo, são ostensivamente glorificados e teatralizados (Maffesoli, 1990 apud Ribeiro, 1996, p. 39-40).

\section{Corpos na marquesa, na passerelle e no podium}

Não pretendemos aqui apresentar uma genealogia que desvende os processos que erigiram um determinado regime do corpo como central - e portanto como normativo, produtor de constrangimentos e de seduções mais ou menos implícitas do que deveria ser a corporalidade enquanto aparição na esfera do social. Mesmo assim, importa destacar três forças que têm um papel central na produção desse efeito. Vamos metaforizá-las com recurso à marquesa do consultório, à passerelle dos desfiles de moda e ao podium das competições desportivas.

Corpo na marquesa: a medicina preventiva, a promoção dos estilos de vida saudáveis, os rastreios populacionais das patologias mais endémicas, as dietas saudáveis; o desenvolvimento das disciplinas do campo da saúde, com a grande expansão da oferta formativa de novas profissões (nutricionismo, diferenciação de múltiplos técnicos de diagnóstico e de reabilitação), mostra como a normatividade do corpo surge já não por contraste com a doença, mas como vontade de manutenção da saúde e como possibilidade de antecipação dos estados mórbidos de modo a controlar o risco do seu desencadeamento. Esse governo do corpo, apelando à sua vigilância e autocuidado, está bem revelado na retórica do "envelhecimento ativo" e na proclamação do aumento da esperança de vida.

Corpo na passerelle: o dos protagonismos e das aparições, de que a moda ou as vernissages sociais são a cúpula. É o corpo adequado ao advento da imagem - se o século XVIII foi o século das luzes,

\footnotetext{
5 Não nos detemos aqui nas razões que terão levado Freud e os seus primeiros discípulos a não seguir esta pista. Seria também um seu discípulo a explorá-la em profundidade, estando na origem das atuais psicoterapias corporais. Referimo-nos a Wilhelm Reich, que pagaria cara a sua heterodoxia, sendo afastado dos círculos psicanalíticos dominantes nos anos 1930.
} 
o final do XX e o atual são os séculos da imagem. Mas a característica da imagem é ser virtual, e a omnipresença do corpo na exibição da imagem é portanto a afirmação do corpo virtual. O corpo virtual não é o corpo, mas algo melhor do que ele: parte dele, mas melhora-o, quem o contempla enquanto imagem não pode contrastá-lo com a realidade corpórea que lhe serviu de molde. A vulgarização do photoshop é o exemplo acabado: o corpo passerelle enquanto ícone de onde irradia o corpo central não é o da aproximação aos corpos reais, mas o da sua mitificação enquanto objeto feito para o deslumbramento.

Podemos remontar aos anos 1950 a importância das modelos profissionais como indutoras da ideia de um corpo-padrão, num contexto de alargamento da moda às classes médias. Soley-Beltran (2011) reconstitui esse percurso histórico e faz em seguida um exercício a que chama de autoetnografia, refletindo sobre as relações entre a moda e o corpo a partir da sua própria experiência de antiga manequim profissional:

Partindo da minha própria experiência, irei apresentar algumas reflexões sobre modelos de moda e publicidade e pessoas públicas que nos apresentam modelos de identidade feminina e, mais genericamente, como recipientes simbólicos de valores culturais intergenéricos. A partir de uma visão interseccional, vou examinar a evolução dos padrões hegemônicos de beleza como mecanismos para definir um padrão de indivíduo e regular a identidade de género, classe e etnia (Soley-Beltran, 2011, p. 84).

Ora, a distância dos corpos reais aos ideais exibidos na passerelle é justamente o espaço onde podem inscrever-se as periferias. As práticas em torno da modelagem do corpo como o body building e o body fitness, os spas, a proliferação de gabinetes de estética e de centros de massagem, a medicina das correções ci- rúrgicas, as dietas para perder peso - estamos de novo, tal como vimos para os corpos na marquesa, perante um governo do corpo que apela à vigilância e ao autocuidado, mudando agora apenas o lugar profissional dos que o instigam e exercem o olhar normalizador.

Corpo no podium: numa sociedade que glorifica a competição, o corpo tem lugar de destaque quando aparece no podium. As olimpíadas da época moderna surgem nos finais do século XIX para celebrar este corpo que triunfa e aparece no seu esplendor. São signos da importância dada ao corpo no podium as piscinas, os ginásios, a proliferação de lugares das mais variadas modalidades de práticas desportivas, os personal trainers, a massificação do jogging, das caminhadas, das corridas de estrada, do cicloturismo, as dietas revigorantes ${ }^{6}$.

\section{Do corpo instituído ao instituinte}

A um corpo instituído pelas técnicas de docilização da sociedade disciplinar, trabalhado de modo tácito pelos processos de incorporação a que já aludimos na secção 1, substitui-se agora um corpo instituinte, trabalhado explicitamente pelo indivíduo enquanto autor da sua própria corporalidade. A disciplina sobre o corpo é agora ditada não pela sua utilidade e docilidade, mas pela sua estética, nas sociedades que passaram a privilegiar a imagem e o aparecer - as sociedades do complexo de Narciso, como as designou Lash (1991). É, ainda, uma disciplina que testemunha a persistência e o sacrifício envolvidos no treino físico e no rigor das dietas, como fica bem evidenciado no excerto seguinte:

O corpo das culturistas é um corpo que sofre com prazer para alcançar a recompensa através de reconhecimento público. Os constantes sacrifícios aos quais se submetem estas mulheres servem como barreiras que as impedem de experienciar algo diferente da rotina ditatorial do corpo perfeito [...] 0 prazer é irreversivelmente associado ao esforço, o sucesso à determinação, e a intensidade de esforço é

\footnotetext{
6 Em A felicidade paradoxal Lipovetsky (2005) faz uma leitura próxima da nossa numa secção que intitula "Corpos no desporto e corpos preguiçosos”, em que fala precisamente da glorificação da competição numa sociedade competitiva, do fascínio pela performance, da admiração que suscitam os corpos harmónicos dos atletas, relacionando isso com o hiperindividualismo. Contrasta-os com os “corpos preguiçosos”, que assistem no sofá a tudo quanto é competição desportiva. Mas Lipovetsky sublinha que é ainda o corpo que está no centro desse hiperindividualista "preguiçoso".
} 
claramente proporcional à angústia provocada pelo olhar do outro (Moreira, 2009, p. 131).

Alguns dos exemplos enumerados a propósito da marquesa, da passerelle e do podium são ambíguos. Com efeito, um spa, um ginásio, um health club podem relevar tanto do corpo na passerelle como do corpo no podium, dependendo da determinação individual de cada frequentador, da forma como subjetiva o trabalho que aí faz e do objetivo que visa atingir. $\mathrm{O}$ mesmo se diga para as dietas, que podem englobar no mesmo ato preocupações com a saúde, com a imagem corporal e com a performance física. O exemplo das praticantes de culturismo estudadas por Moreira (2009) é a este respeito exemplar: valorizam a forma do corpo e a harmonia com que se apresentam nas competições, mas igualmente o esforço e o sacrifício para atingir performances competitivas. Corpos na passerelle, personificados no estudo de Moreira por manequins, e corpos no podium, personificados por culturistas, estariam ambos na mesma procura, levando aos limites o regime que está a tornar-se normativo, bem sintetizado por Ribeiro (1996):

Quer isto dizer que as pessoas já não se satisfazem com desempenhos corporais suficientes e rotineiros, nem com o medíocre bem-estar que decorre da satisfação das suas necessidades naturais; reclamam do seu corpo desempenhos de excelência, capazes de produzir emoções fortes saciando desejos ousados. Ao ideal de moderação (ou de modéstia) substituiu-se a paixão do desafio e do excesso: na originalidade das sensações, na extravagância da imagem, nos "efeitos especiais" da mise en scène (Le Breton, 1992, p. 40).

Mas esse corpo expandido limita-se a iludir, com tais "efeitos especiais" que ostenta nos espaços de visibilidade do social, o regime de normalização que o sujeita. Voltando ainda a manequins e culturistas, “ambos são corpos dirigidos para a ação, investindo em práticas de reconstrução da forma corporal.
Ambos são corpos dóceis, segundo Foucault, corpos moldados e disciplinados pelo exercício físico como pela alimentação, com o intuito de atingirem o corpo" (Moreira, 2009, p. 138).

Ou seja, a corporalidade modal aproxima-se duma imagem de corpo ideal que se passeia na passerelle ou se ostenta no podium, elevando as exigências e aumentando portanto a probabilidade de se ficar aquém da imagem socialmente valorizada - eis, como veremos na secção seguinte, um eficaz mecanismo de produção de periferias do corpo.

\section{Corpos periféricos}

Nas secções anteriores avançamos com alguns elementos suscetíveis de compreender a construção social de uma normatividade em torno do corpo, que vai constituir-se como lugar a partir do qual produzimos distâncias, estigmas e rejeições e, consequentemente, aquilo a que chamaremos corpo periférico. A crescente visibilização do corpo nas sociedades ocidentais, revelada nas metáforas da marquesa, do podium e da passerelle, tem como contraponto o modo como retiramos o corpo periférico das vistas. Debrucemo-nos agora em mais detalhes sobre ele, começando por explicitar a que é que nos referimos ao invocá-lo.

Corpo periférico é o das secreções, dos cheiros, dos ruídos - tudo quanto a educação do indivíduo civilizado, que se afasta decisivamente da barbárie, vai adestrar com método ${ }^{7}$.

Mas o corpo periférico é também aquele que tapamos porque foge da geometria da beleza, da esquadria da desenvoltura física. 0 traje é esta produção que impede o corpo de se expor à evidência da sua imperfeição, sujeitando o seu portador ao risco da periferização. Por sobre o corpo construímos toda uma arte das ocultações, do traje à cosmética, da prótese à cirurgia estética. Estamos, pois, perante um corpo construído numa espécie de simulação: a roupa, os adereços, a maquilagem, associados a técnicas como a cirurgia plástica, a lipoaspiração, os tratamentos de beleza. Mesmo fazendo parte de um processo de produção, voltam-se para o imaginário,

7 Inspiramo-nos em Mary Douglas (1970) quando explora as propriedades simbólicas do corpo, incluindo os seus aspectos mais ou menos ocultados, como orifícios e secreções. Remetemos à secção 1 deste artigo, onde apresentámos brevemente o seu conceito de "símbolo natural". 
ajudam homens e mulheres a mascararem o próprio corpo, escondendo uns detalhes e ressaltando outros (Rosário, 2006).

David Le Breton (1999) propõe a metáfora do corpo-rascunho, que é preciso melhorar a todo o instante. Viveríamos um tempo em que o corpo está, nas palavras do autor, sob suspeita, o que instauraria a vontade de manipulá-lo. 0 que acontece aos que não conseguem vencer essa suspeita?

Ficam vulneráveis a algum tipo de condenação pode ser a do simples olhar desagradado dos outros, evoluir para o evitamento, acabar na ostracização. Analisemos brevemente dois exemplos.

\section{Deformidades, amputações e defeitos físicos}

As deformidades do corpo, inscritas à nascença ou adquiridas no trajeto existencial, são a mais evidente fonte de periferização, magistralmente analisadas no clássico Stigma, de Goffmann (1963b). São vividas no silêncio, como o demonstra um passeio pela praia no verão. Os corpos periféricos estão proibidos de ir à praia? 0 que revela então a sua quase ausência balnear? Que regime social de ocultação ou de rejeição dessas diferenças isso revela? Um regime que fez do corpo o veículo imediato de afirmação no contexto do hiperindividualismo: à retração do corpo social responde-se com a expansão do corpo material, afirmando com ele a sua presença no mundo. À medida que se torna uma arma importante na sociedade da imagem, os seus desvios tornam-se também mais comprometedores, e o modo mais simples de fugir à tirania do olhar que avalia é evitá-lo. Olhar um corpo periférico incomoda, porque nos confronta com o acidente - e o narciso, como muito bem mostrou longamente a psicanálise, é frágil.

O ableismo surge então como um importante conceito por se debruçar na análise das crenças, processos e práticas ligados à produção de uma norma corporal que é essencial para se ser considerado totalmente humano (Campbell, 2008 apud Loja; Costa; Menezes, 2011). 0 evitamento, o medo, a ajuda ou a curiosidade são respostas comuns escolhidas por pessoas sem deficiência para interagir com as pessoas com deficiência, negando-lhes as suas narrativas de adaptação quotidianas e minando o seu bem-estar e sentimentos de valorização pessoal. Hughes (1999, p.163) argumenta que a pena, o medo e o nojo são "os principais blocos de construção da infraestrutura emocional do ableismo".

Retirado da vida social corrente, o corpo periférico revelado na deformidade, na amputação ou qualquer degradação visível, reaparece no espaço público como sinal de margem no mendigo. Paradoxalmente, pode transformar-se, neste caso, num capital corporal, para utilizarmos a expressão de Bourdieu (1979).

\section{A obesidade}

Os corpos na marquesa têm sido submetidos a sucessivas mensagens dos profissionais de saúde sobre o excesso de peso como fator de risco em várias patologias; os corpos passerelle têm afirmado a magreza como qualidade valorizada; os corpos no podium são medidos e pesados nos ginásios, que lhes avaliam agora o índice de massa corporal logo na primeira visita. A gordura está proscrita, nesta proclamação generalizada dos corpos saudáveis, harmónicos e vigorosos?

De tal modo esta periferia do corpo que é a gordura se tornou estigmatizante que uma das formas do adoecer psíquico na adolescência é a anorexia nervosa, doença resultante da escravidão da imagem ${ }^{8}$.

Uma investigação recente, revendo uma grande quantidade de literatura no domínio, mostrou como a principal razão invocada pelos adolescentes de ambos os sexos para as condutas de restrição severa das dietas alimentares era a crença de que a imagem do corpo seria decisiva para atraírem pessoas do sexo oposto (Martins, 2013). Por outro lado, encontrou-se evidência acerca do facto de, no seu contexto familiar, ocorrerem críticas frequentes à aparência física desde a infância, pressões para a realização de dietas e exercício físico, e grande

8 Utilizamos aqui o termo escravidão no seu sentido etimológico: "adicção" significa etimologicamente "escravidão". Ora, a anorexia nervosa tem sido proposta por alguns especialistas enquanto adicção, apresentando a sua instalação, desenvolvimento e manifestações clínicas uma série de semelhanças com as adicções às drogas. Para essa discussão ver Martins (2011, 2013). 
valorização da imagem (Martins, 2011, 2013).

Outra modalidade da adicção relacionada com a imagem corporal é a vigorexia, caracterizada pela sujeição a um intenso trabalho físico dirigido ao aumento do volume e massa musculares, de modo a obter uma modelagem das suas formas, suando diariamente no ginásio num regime de treino quase sacrificial - vimos já, com Moreira (2009), como este sacrifício era valorizado. A vigorexia aparece como uma adicção sem químico: "O aumento do número de jovens que sofrem com transtornos da imagem, como bulimia, anorexia e vigorexia é um reflexo da obsessão com as formas do corpo, cultivado através de dietas e até mesmo cirurgias estéticas" (Correia; Queirós, 2006, p. 57).

A obesidade é o esbatimento das formas, no limite o seu desaparecimento engolido na forma única do cilindro. O recente concurso televisivo que recrutava obesos e os submetia a um programa de emagrecimento é bem o analisador do medo de cair nesse tipo de periferia do corpo ${ }^{9}$. Durante algumas semanas, os selecionados, pessoas de ambos os sexos com pesos quase sempre acima dos $150 \mathrm{~kg}$, submetiam-se a um severo regime tanto de treino físico como de correção e restrição dietética, evidenciando e verbalizando um sofrimento físico no limite da dor. A balança funcionava ao fim de cada dia como o juiz que os absolvia ou que os condenava, prescrevendo então novas penas no duro combate contra as calorias. 0 discurso dos participantes girava em torno do sacrificial: um esforço desmedido, suor e dor, castigo infligindo para merecer a redenção que é a vitória do corpo magro.

Tratava-se de uma competição, introduzindo portanto o corpo no podium como meta suprema do corpo periférico do obeso. Essa periferia era bem evidenciada no discurso dos participantes, que referiam com abundância argumentos do quanto os seus corpos gordos os privavam de uma vida normal. Isso era reforçado pelos vencedores, que testemunhavam o quanto a sua vida mudara desde as alterações na sua aparência - como que se a vitória sobre a obesi- dade lhes devolvesse a possibilidade de um regresso à vida social de que tinham sido privados.

Corpos na passerelle e no podium estão, afinal, próximos, revelando ambos uma característica evidenciada já no trabalho de Moreira: "O ponto comum destes dois grupos de estudo (manequins e culturistas) surgiu no combate à gordura, à flacidez e à celulite. Esta preocupação corrente é inerente ao descuido e falta de disciplina imposta ao próprio indivíduo" (2009, p. 136).

Eis como traços alvo de reprovação (descuido, falta de disciplina) nos aproximariam do risco de sermos um corpo periférico. Simetricamente, esse corpo periférico seria o sinal inequívoco do descuido - como que traindo, pela verdade posta a nu pelas formas corporais - o disfarce com que vamos iludindo do olhar dos outros traços psicológicos desvalorizados.

\section{Conclusão}

A periferia, termo da linguagem da geometria, não indica distância, mas disposição espacial em relação ao centro (Herrera, 2008). Se o termo se vulgarizou na linguagem que fala o urbano, onde a periferia é pensada como categoria socioterritorial, deslocámo-nos ao longo deste artigo para um sentido mais próximo do que lhe é dado na geometria e procurámos esclarecer a disposição das corporalidades em relação a um centro, constituído pelo espaço simbólico do corpo modal. Com este exercício evidenciámos a instrumentalidade das corporalidades na interação social. A centralidade corpórea, construída num processo incessante a partir das imagens irradiadas dos corpos na marquesa, na passerelle e no podium, torna-se uma instância com grande poder no jogo social. Definem-se assim disposições em relação à centralidade dotadas de efeitos performativos: o corpo não é a materialidade física de um sujeito psicológico ou de uma identidade social - ele é o próprio sujeito. Ganha aqui toda a sua expressão a frase que temos ouvido de vários

90 reality show The biggest loser da cadeia televisiva NBC, iniciado em 2004 nos EUA, que apareceu em Portugal com o título Peso pesado, iniciado em 2011, e no Brasil, em 2005, com o nome O Grande perdedor e, pouco depois, Quem perde ganha. 
psicoterapeutas corporais que diz nós não temos um corpo, nós somos o corpo.

Esse nosso percurso fornece ainda uma leitura possível para alguns processos de interação social produtores de estigma e mesmo, como exemplificámos a partir da anorexia, de adoecimento mental. Mas fornece, também, uma leitura para a ascensão atual das disciplinas relacionadas com a imagem do corpo: cirurgia plástica reconstrutiva e estética, modelagem corporal a partir do trabalho de ginásio, surgimento de novos profissionais como o personal trainer, reemergência do termal, redescoberta do spa (sanitas per acqua) agora potenciado em múltiplos contextos de lazer e bodycare, da massagem, dos tratamentos e limpezas de pele, do melhoramento da postura e da respiração com a profusão de técnicas como a reeducação postural global, a antiginástica, o rolfing ou o pilates, entre tantas outras.

A medicina, que se tinha imposto como prática e profissão desvendando o interior do corpo, vira-se agora para o seu exterior. No século XIX foram decisivas, para a sua afirmação no contexto positivista da formação de novas ciências, a técnica da autópsia, a endoscopia, a anatomofisiologia, a citologia e a histologia - o corpo por dentro. São hoje decisivos os avanços que permitem a intervenção na própria corporalidade - o corpo por fora. Outra linha evolutiva detetámo-la na passagem da incorporação, que aqui exemplificámos a partir das técnicas disciplinares em ordem a corpos dóceis e úteis, para um regime mais autodeterminado, a partir da reivindicação do direito ao corpo e às manifestações do corpo vivido.

Dito de outro modo, ao corpo instituído seguiu-se o corpo instituinte. Com a produção de corpos periféricos a partir de uma centralidade corpórea afirmada como um valor de per se, estamos agora perante os corpos destituídos. Em um tempo que alarga as clivagens, aprofunda as desigualdades e fabrica periferias imensas, como se têm encarregado de nos mostrar inúmeras investigações do campo dos estudos urbanos ${ }^{10}$, também o corpo pode ser um território destituído. Se Bourdieu (1979) falou num capital corporal, afirmando que as pro- priedades corporais podem funcionar como capital para a obtenção de lucros sociais, para conceder à representação dominante do corpo um reconhecimento incondicional, os corpos periféricos são os excluídos, ou pelo menos os marginalizados desse capital.

\section{Referências}

ALMEIDA, M. V. de. O corpo na teoria antropológica. Revista de Comunicação e Linguagens, Lisboa, n. 33, p. 49-66, 2004. BOURDIEU, P. La distinction: critique sociale du jugement. Paris: Les Éditions de Minuit, 1979.

CORREIRA, C.; QUEIRÓS, P. Corpo, jovens e prática de musculação: um estudo em frequentadores de academia na região do Grande Porto. 2006. Dissertação (Mestrado em Ciências do Desporto) - Faculdade de Desporto da Universidade do Porto, Porto, 2006.

CUNHA, N. V. da; FELTRAN, G. de S. Novos conflitos nas margens da cidade. In: Sobre periferias. Novos conflitos no Brasil contemporâneo. Rio de Janeiro: Lamparina, 2013. p. 9-15.

DOUGLAS, M. Purity and danger; an analysis of concepts of pollution and taboo. Londres, Routledge, 1966.

DOUGLAS, M. Natural symbols: explorations in cosmology. London: Barrie \& Rockliff, 1970.

FERREIRA, V. S. Resgates sociológicos do corpo: esboço de um percurso conceptual. Análise Social, Lisboa, v. 208, n. 3, p. 2182-2999, 2013.

FOUCAULT, M. L'ordre du discours. Paris: Gallimard, 1971.

FOUCAULT, M. Surveiller et punir. Paris: Gallimard, 1975.

GOFFMAN, E. Behavior in public places: notes on the social organization of gatherings. New York: Free Press, 1963a.

10 Ver a este respeito a revisão do tema da periferia urbana empreendida por Cunha e Feltran (2013), em que o lado destituído da periferia é bem evidenciado 
GOFFMAN, E. Stigma: notes on the management of spoiled identity. Engelwood Cliffs: PrenticeHall, 1963b.

HALL, S.; JEFFERSON, T. Resistance through rituals: youth subcultures in post-war Britain. London: Hutchinson, 1975.

HERRERA, P. A. Desarrollos urbanos e inversiones turísticas costeiras. Urbano, Santiago, v. 18, p. 1623, nov. 2008.

HUGHES, B. The constitution of impairment: modernity and the aesthetic of oppression. Disability \& Society, New York, v. 14, n. 2, p. 155172, 1999.

JUNG, H. Y. Phenomenology and body politics. Body \& Society, London, v. 2, n. 2, p. 1-22, 1996.

LANGMAN, L. Punk, porn and resistance: carnivalization and the body in popular culture. Current Sociology, London, v. 56, p. 657-677, jul. 2008.

LASCH, C. The culture of narcissism: American life in an age of diminishing expectations. New York: W. W. Norton \& Company, 1991.

LE BRETON, D. L'adieu au corps. Paris: Métailié, 1999 .

LIPOVETSKY, G. A era do vazio. Lisboa: Relógio d'Água, 1989.

LIPOVETSKY, G. A felicidade paradoxal: ensaio sobre a sociedade do hiperconsumo. Lisboa: Edições 70, 2005.

LOJA, E.; COSTA, M. E.; MENEZES, I. Views of disability in Portugal: 'fado' or citizenship?. Disability \& Society, London, v. 26, p. 567-581, ago. 2011.

MARTINS, A. C. P. Razões de saúde mental e social na administração do corpo adolescente: anorexia nervosa e uso de drogas. In: CUNHA, M. I.; DURAND, J-Y. (Orgs.). Razões de Saúde: poder e administração do corpo: vacinas, alimentos, medicamentos. Lisboa: Fim de século, 2011. p. 5778 .

MARTINS, A. C. P. Linhas e riscos de se tornar adulto: drogas, dietas e transgressões de género.
2013. Tese (Doutorado em Psicologia) - Faculdade de Psicologia e de Ciências da Educação da Universidade do Porto, Porto, 2013.

MARTINS, C. S. S. Casa Pia de Lisboa como instituição total e o governo do aluno surdo. Educação, sociedade e culturas, Porto, v. 30, p. 95-111, 2010.

MOREIRA, M. Entre a estética do corpo da moda e do corpo do culturismo: estudo exploratório a partir da opinião de manequins e de praticantes de culturismo. 2009. Dissertação (Mestrado em Ciências do Desporto) - Faculdade de Desporto da Universidade do Porto, Porto, 2009.

O'NEILL, J. Five bodies: the human shape of modern society. New York: Cornell University Press, 1985 .

PELEGRINI, T. Imagens do corpo: reflexões sobre as acepções corporais construídas pelas sociedades ocidentais. Revista Urutágua, Maringá, n. 8, s/p, jan. 2006. Disponível em: $<$ www.urutagua.uem.br/oo8/o8edu_pelegrini. htm>. Acesso em: 12 jan. 2015.

PEREIRA, A. L. S. Reflexões sobre o fenómeno da "centralidade" a partir do quadro teórico da "Antropologia da Cidade". Ponto Urbe, São Paulo, v. 11, 2012.

PEREIRA, P. P. G. De Corpos e Travessias: a grande divisão e o campo da saúde. Saúde e Sociedade, São Paulo, v. 20, n. 1, p. 66-75, jan./mar. 2011.

RIBEIRO, A. O corpo vai ao psicólogo. Cadernos de Consulta Psicológica, Porto, v. 12, p. 39-43, 1996.

ROSÁRIO, N. M. Mundo contemporâneo: corpo em metamorphose. [S. l.]: [s. n.], 20o6. Disponível em: <www.comunica.unisinos.br $>$. Acesso em: 12 jan. 2015.

RUI, T. C. Corpos abjetos: etnografia em cenários de uso e comércio de crack. 2012. Tese (Doutorado em Antropologia Social) - Instituto de Filosofia e Ciências Humanas da Universidade Estadual de Campinas, Campinas, 2012.

SEPARAVICH, M. A.; CANESQUI, A. M. Girando a lente socioantropológica sobre o corpo: uma breve 
reflexão. Saúde e Sociedade, São Paulo, v. 19, n. 2, p. 249-259, jun. 2010.

SOLEY-BELTRAN, P. Cuerpos ideales: una aproximación interdisciplinaria al estudio de las modelos de moda. Quaderns de l'Institut Català
d'Antropologia, Barcelona, v. 26, p. 83-110, jun. 2011.

TURNER, B. S. The body \& society: explorations in Social Theory. London: Sage Publications, 1996.
Contribuição dos autores

Todos os autores foram responsáveis pela concepção, elaboração e revisão do artigo.

Recebido: 19/02/2015

Reaprovado: 26/06/2015

Aprovado: 09/09/2015 